\title{
Evaluation of caries-affected dentin with optical coherence tomography
}

\section{Cynthia Soares de Azevedo(a) Luciana Cardoso Espejo Trung(a) Maria Regina Lorenzetti Simionato ${ }^{(b)}$ \\ Anderson Zanardi de Freitas ${ }^{(\mathrm{c})}$ Adriana Bona Matos ${ }^{(a)}$}

\footnotetext{
(a) Department of Operative Dentistry, Dental School, University of São Paulo (USP), São Paulo, SP, Brazil.

(b) Department of Microbiology, Institute of Biomedical Sciences (ICB), University of São Paulo (USP), São Paulo, SP, Brazil.

(c) Nuclear and Energy Research Institute (IPEN-CNEN/SP), São Paulo, SP, Brazil.
}

Declaration of Interests: The authors certify that they have no commercial or associative interest that represents a conflict of interest in connection with the manuscript.

Corresponding Author:

Adriana Bona Matos

E-mail: bona@usp.br

Received for publication on May 20, 2011 Accepted for publication on Aug 26, 2011

\begin{abstract}
The purpose of this study was to evaluate the degree of demineralization of artificially induced caries-affected human dentin by an in vitro microbiological method. The occlusal surfaces of 6 human molar teeth were abraded until a flat surface was obtained, and the enamel was removed to expose the occlusal dentin surface. These teeth were sectioned in 12 halves in the vestibular-lingual direction and divided into 3 groups according to the period length of the microbiological essay $(n=4): G 1,7$ days; G2, 14 days; and G3, 21 days. The surfaces of all specimens were protected by an acid-resistant nail varnish, except for a window where the caries lesion was induced by a Streptoccocus mutans biofilm in a batch-culture model supplemented with $5 \%$ sucrose. The specimens were then analyzed by optical coherence tomography (OCT) with a super-luminescent light diode $(\lambda=930 \mathrm{~nm}$ ) with $6.0-\mu \mathrm{m}$ lateral and longitudinal resolution (in the air). Qualitative and quantitative results (images and average dentin demineralization, respectively) were obtained. The mean demineralization depths were $(\mu \mathrm{m}) 235 \pm 31.4,279 \pm 14$, and $271 \pm 8.3$ in groups 1, 2, and 3, respectively. In addition, no significant change was observed in the lesion mean depth from 7 days of cariogenic challenge on. In conclusion, OCT was shown to be an efficient and non-invasive method to detect the depths of lesions caused by demineralization. Further, a seven-day demineralization time was considered sufficient for caries-affected dentin to be obtained.
\end{abstract}

Descriptors: Tomography; Dental Caries; Microbiology.

\section{Introduction}

Dental caries is one of the most prevalent chronic diseases. Its treatment has changed significantly in recent years, since the current management of caries involves non-invasive techniques and partial removal of carious dentin. ${ }^{1}$ Therefore, adhesive restorations are widely indicated, and adhesives must adequately interact with caries-affected dentin, which is demineralized but prone to remineralization.

It is important to point out that most bond strength tests are performed on healthy dental tissue, which is not considered a clinically relevant substrate. Since the characteristics of caries-affected dentin are different from those of healthy dentin, the hybrid layer associated with it will also be different. ${ }^{2}$ Also, contradictory results have been obtained from bond strength tests performed on natural caries-affected dentin. ${ }^{3,4}$ Therefore, studies in which standardized caries-affected dentin is used 
contribute significantly to this area of knowledge.

Numerous in vitro caries models have been reported. ${ }^{5}$ In the chemical method, the acidified gel technique and $\mathrm{pH}$-cycling method are included; in contrast, microorganism strains with known cariogenicity are used in the microbiological method in a way whereby the acid product of their metabolism demineralizes the dental structure. ${ }^{5}$ More elaborate systems involving chemostats, flowcells, artificial mouths, and constant-depth film fermentors have been developed in an attempt to better mimic the environment of the oral cavity. ${ }^{5}$ However, their high cost and complex apparatus requirements are often limiting factors. ${ }^{5}$ Some authors ${ }^{6}$ believe that the bacterial model is the closest to the conditions found in vivo. In the present study, the microbiological method modified by Gama-Teixeira et al. ${ }^{7}$ was used to obtain caries-affected dentin, but the amount of time necessary to produce it has not yet been established.

Since the artificially obtained substrate will be used in future laboratory tests, demineralization depth must be measured by a non-destructive method. Image diagnosis modalities such as ultrasonography, computerized tomography, and magnetic resonance are technologies that had a significant impact on medical research and clinical practice, since new tools are needed for the non-destructive assessment of the depth and severity of caries lesions. ${ }^{8}$ In optical coherence tomography (OCT), spatial resolution can be as high as 10 times that obtained by the ultrasound technique. ${ }^{9}$ OCT is based on lowcoherence laser interference principles, and is similar to the ultrasound technique in various respects, although electromagnetic radiation is used instead of sound waves. ${ }^{10}$

OCT is a non-invasive technique for caries detection that allows for both following the process of dental tissue demineralization ${ }^{11}$ and premature detection of the presence of caries. In addition, it has the potential to determine the locations and depths of lesions, as well as to detect hidden and secondary caries that occurs at the tooth-restoration interface. ${ }^{11}$ The use of electromagnetic radiation in the near-infrared region, instead of ionizing radiation (x-rays), which is potentially mutagenic, is among its advantages.

The aim of this study was to evaluate the degree of demineralization of artificially induced caries-affected human dentin by an in vitro microbiological method.

\section{Methodology Artificial occlusal caries}

Healthy human molar teeth were cleaned with periodontal curettes and a rubber cup with pumice paste and water, and were stored in distilled water $\left(4^{\circ} \mathrm{C}\right)$ until use. Approval was obtained from the Ethics Committee (University of São Paulo, Dental School, FOUSP, protocol \#115/2010).

The occlusal surfaces of 6 human molar teeth were abraded with a sandpaper disc until a flat surface was obtained and the occlusal dentin surface was exposed. These teeth were sectioned in half in the buccal-lingual direction, and the 12 resulting halves were randomized and distributed among 3 experimental groups $(n=4)$.

Half the area of the prepared teeth was covered with acid-resistant nail varnish (Colorama, CEIL Coml Exp Ind Ltda., São Paulo, Brazil). The dental halves were sterilized with gamma ray irradiation (25 kGy). Caries lesions were then induced in vitro with the use of a bacterial system, following the method modified by Gama-Teixeira et al. ${ }^{7}$

S. mutans (ATCC 25175) was incubated in Tryptic Soy Broth media (TSB, Difco-Becton, Dickinson and Company-Sparks, Detroit, USA) supplemented with $5 \%$ sucrose $\left(37^{\circ} \mathrm{C}, 24 \mathrm{~h}\right)$ to obtain bacterial growth. Bacteria were spread on the surface of Tryptic Soy Agar (TSA, Difco-Becton, Dickinson and Company-Sparks, Detroit, USA) solid culture medium to obtain isolated colonies, which were reincubated $\left(37^{\circ} \mathrm{C}, 48 \mathrm{~h}\right)$. After growth, the colonies were transferred into tubes containing TSB (with $5 \%$ sucrose) to initiate microorganism preconditioning with sucrose (6 days). The dental halves of the same group were immersed in a solution $(300 \mathrm{~mL}$ of TSB with $5 \%$ sucrose and $3 \mathrm{~mL}$ of inoculum broth) and were maintained therein for 7 (group 1), 14 (group 2), and 21 (group 3) days, being transferred to a fresh tube every $24 \mathrm{~h}$. During the incubation periods, tests were performed to check for the presence 
of bacterial contaminants, and after the specified time periods, the dental halves were removed from the bacterial system.

At the end of the cariogenic challenge, the biofilm adhering to the surface was carefully removed, and the specimens were washed with deionized water. Immediately before the demineralization depth was read, the acid-resistant nail varnish was mechanically removed from the surfaces of all specimens.

\section{OCT imaging}

\section{System configuration}

In the most common OCT systems, a Michelson interferometer is used to provide a cross-section image of the scattering specimens, with non-invasive evaluation and without contact with their surfaces. In this system, the light is conducted by an optical fiber as far as a $2 \times 2$ coupler, where the light is split into 2 beams, one of which is sent to a reference mirror and the other to the sample.

In this OCT system (SR930 Thorlabs Inc., Newton, USA), a SLED (super-luminescent light-emitting diode; $\lambda=930 \mathrm{~nm}$ ) provided $\mathrm{A}$ and $\mathrm{B}$ scans with 4.0and $6.0-\mu \mathrm{m}$ resolution, respectively. The system was able to produce up to 4 frames per sec, thus providing real-time images $(2000 \times 512$ pixels; equivalent to a width $\times$ height area of $6000 \times 1581 \mu \mathrm{m}^{2}$ ).

The images were acquired from the central regions of the exposed windows, generating images from both exposed and varnish-protected (control) surfaces. The images of the caries-affected dentin were obtained by OCT for different exposure periods $(7,14$, and 21 days) and were compared according to demineralization depth (described above). If any tissue loss occurred due to the demineralization process, the amount of lost tissue was included in the calculation, with the adjacent sound dentin as the initial reference.

\section{Results}

\section{Quantitative analysis}

Depth values (in $\mu \mathrm{m}$ ) of minimum, maximum, and mean demineralization are shown in Table 1. Regarding the mean demineralization depth, the values calculated for all groups were similar, when demineralization depths for 7,14 , and 21 days were compared.

\section{Qualitative analysis}

OCT renders 3 types of image: traditional (similar to that generated by ultrasound equipment), colored, and inverted (white, with the demineralized region/line in gray or black). In the present study, traditional and inverted images were obtained for each of the 12 specimens. Representative images of each experimental group were selected to illustrate the OCT characteristics of the specimens subjected to cariogenic challenge (Figures 1A, 1B, 2A, 2B, 3A, and $3 \mathrm{~B})$. All Figures present a vertical bar that di-

\begin{tabular}{|c|c|c|c|c|c|}
\hline \multirow{13}{*}{$\begin{array}{l}\text { Table } 1 \text { - Values for } \\
\text { demineralization depth in function } \\
\text { of different exposure periods of } \\
\text { cariogenic challenge, according to } \\
\text { experimental groups. }\end{array}$} & Group & Specimen \# & Min-max $(\mu \mathrm{m})$ & Mean $(\mu \mathrm{m}) \pm S D$ & Mean $(\mu \mathrm{m}) \pm \mathrm{SD}$ per Group \\
\hline & \multirow{4}{*}{1} & 1 & $225-231$ & $228 \pm 3$ & \multirow{4}{*}{$235 \pm 31.4$} \\
\hline & & 2 & $188-200$ & $194 \pm 6$ & \\
\hline & & 3 & $244-269$ & $256 \pm 12.5$ & \\
\hline & & 4 & $256-269$ & $263 \pm 6.5$ & \\
\hline & \multirow{4}{*}{2} & 5 & $275-306$ & $291 \pm 15.5$ & \multirow{4}{*}{$279 \pm 14$} \\
\hline & & 6 & $225-300$ & $263 \pm 37.5$ & \\
\hline & & 7 & $263-281$ & $272 \pm 9$ & \\
\hline & & 8 & $238-344$ & $291 \pm 53$ & \\
\hline & \multirow{4}{*}{3} & 9 & $188-363$ & $275 \pm 87.5$ & \multirow{4}{*}{$271 \pm 8.3$} \\
\hline & & 10 & $269-288$ & $278 \pm 9.5$ & \\
\hline & & 11 & $256-263$ & $259 \pm 3.5$ & \\
\hline & & 12 & $269-275$ & $272 \pm 3$ & \\
\hline
\end{tabular}



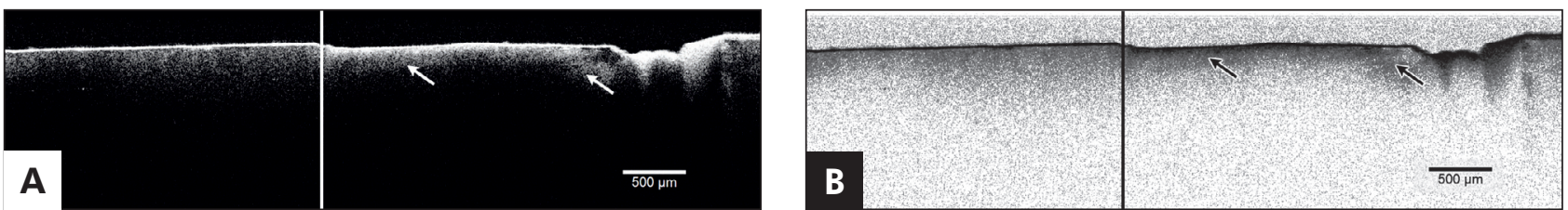

Figures 1A and 1B - OCT image after 7 days of cariogenic challenge. A slight loss of structure is observed on the surface. Higher demineralization and loss of structure are observed at the tooth-varnish interface, due to a higher accumulation of bacterial plaque at both the center and the right of the image. In the images, demineralization is observed in white (1A) and dark gray/black (1B) (arrows). Bar $=500 \mu \mathrm{m}$.
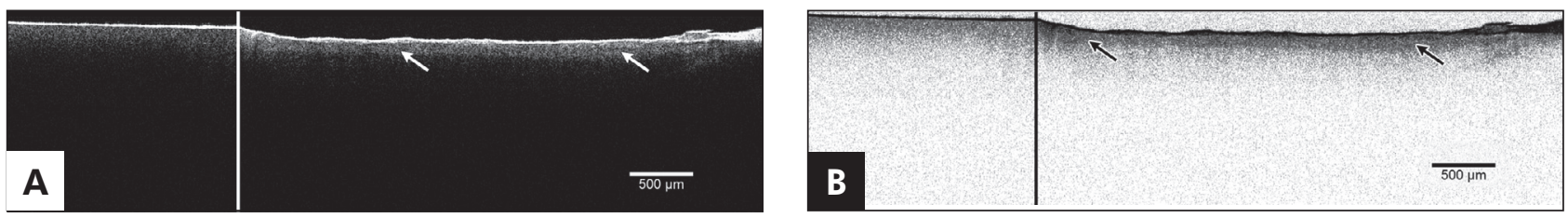

Figures 2A and 2B - OCT image after 14 days of cariogenic challenge. The loss of structure is more pronounced, and a step can be observed between the exposed surface and that protected by the acid-resistant varnish. In the images, demineralization is observed in white (2A) and dark gray/black (2B) (arrows). Bar $=500 \mu \mathrm{m}$.
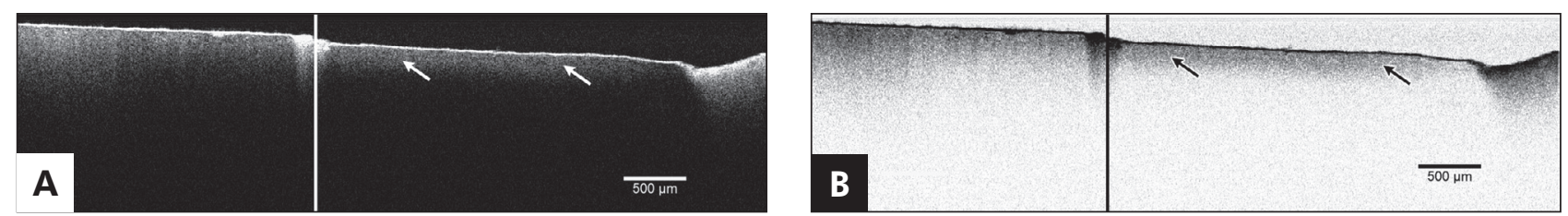

Figures 3A and 3B - OCT image after 21 days of cariogenic challenge. Significant variation was not observed in dentin demineralization in the period between 14 and 21 days. Loss of structure (step between the exposed surface and that protected by acid-resistant varnish) is observed. In the images, demineralization is observed in white (3A) and dark gray/black (3B) (arrows). The regions where higher loss of structure is observed are directly related to the higher accumulation of bacterial plaque. Bar $=500 \mu \mathrm{m}$

vides the dentin surface into demineralized (right) and non-demineralized (left) sides. Demineralization depth is indicated by the presence of arrows.

The severity of demineralization could be detected by OCT and is indicated by the amount of light gray in the traditional image (Figures $1 \mathrm{~A}, 2 \mathrm{~A}, 3 \mathrm{~A}$ ) and dark gray (Figures 1B, 2B, 3B) in the inverted image mode. Much severe demineralization could be detected at 14 and 21 days, when compared with that at 7 days of cariogenic challenge.

\section{Discussion}

Caries-affected substrate obtained in vitro by the microbiological method contributes significantly to the field of dentin adhesion, because it will allow laboratory tests to be performed on standard cariesaffected dentin, which is a clinically relevant sub- strate. ${ }^{12-14}$ The microbiological method allowed us to artificially produce caries-affected dentin effectively induced from 7 days on.

The achievement of artificial caries lesions that are morphologically similar to natural caries lesions $^{14}$ was a relevant factor in the choice of the microbiological method, although caries lesions thus obtained show low hardness levels compared with those obtained by chemical or pH-cycling methods. ${ }^{15}$ However, the same authors state that the microbiological method is more adequate for obtaining lesions with an evident infected dentin layer, which can be removed.

OCT has already been shown to be effective in detecting premature and secondary caries, ${ }^{16,17}$ and was chosen as the diagnostic method for the evaluation of demineralization depth. The images ob- 
tained by OCT confirm that this method is effective in evaluating the depth of demineralization caused by induction of caries in vitro from 7 days on. The images clearly show that the demineralization process is occurring in the specimens after different periods of exposure to the bacterial challenge. Associating qualitative and quantitative results, we could observe that the demineralization depth was almost the same when the 3 periods of challenge were compared. However, a close examination of the images allows for the identification of a more severe and uniform demineralization at 14 and 21 days, when compared with samples demineralized for only 7 days.

Freitas et al..$^{18}$ evaluated the demineralization process up to 11 days, and observed exponential bacterial growth until about 9 days. These authors relate this fact to the exhaustion of nutrients available in the culture, accumulation of inhibitory metabolites and metabolic end-products, or lack of biological space. ${ }^{18}$ This result was confirmed in the present study, because an increase in the demineralization depth was not observed from 7 days on. We believe that the nutrient exhaustion hypothesis does not apply to our conditions, since the nutrients were supplied every $24 \mathrm{~h}$. However, accumulation of metabolites and end-products as well as lack of biological space could be the causes for the non-progression in lesion depth from 7 days on.

Such findings can be explained: The biofilm that naturally accumulates on tooth surfaces is a complex community comprised of more than 500 bacterial species. ${ }^{19,20}$ The early colonizers are predominantly streptococci. To initiate heterogeneous bacterial interactions, diffusible signals may play important roles, and processes of co-adhesion and co-aggregation of distinct microorganisms contribute to biofilm maturation. In the presence of sucrose, glucosyltransferase enzymes produce water-insoluble glucan polysaccharides and may contribute to S. mutans colonization. ${ }^{21}$ It is likely that the initial colonizing bacteria create a favorable environment for new invaders, due to the presence of metabolites inhibitory to those bacteria. This would favor the survival of other species more able to adapt to the new habitat and replace the initial species. In this study, the biofilm consisted of only $S$. mutans, and, consequently, there was no competitive or inhibitory substance produced by other species. Moreover, the bacterial deposition that occurred during the cariogenic challenge days rendered the biofilm thicker. Nevertheless, the development of a biofilm having a high bacterial cell density increases the concentration of signaling molecules, increasing the possibilities of expression of mechanisms for biofilm control, such as quorum sensing or production of surface proteins. ${ }^{22,23}$ Although no biomass measurements were made in this study, the results show a nondeepening of demineralization in the period up to 21 days, which would be explained because a toothick layer of bacterial deposit was formed in the caries induction process.

S. mutans, used in the present study, is an initial colonizer, and has a recognition system that allows the bacterial surface to connect with the acquired dental biofilm. S. mutans has characteristics, especially in the presence of sucrose (the source of nutrients used in this study), which trigger its adhesion to the tooth and allow other bacterial cells to coaggregate therein. In the accumulation phase, multiplication of the initial colonizers and their volume increase occur, and adhesion of different colonizers is likely to occur. Thus, microbial succession is the next phase in the development of dental caries. This last process did not occur because our study used a mono-species biofilm. Perhaps additional studies using different strains of $S$. mutans with known cariogenicity would be important for comparing results obtained with ATCC 25175.

The light beam scan in OCT generates a backscattering signal according to the depth of that specimen region. The images obtained by OCT show that the signal in the sample regions affected by demineralization is deeper than in the healthy regions. As a consequence, the backscattering is lower in demineralized regions, allowing for deeper penetration of the laser beam into the sample. The equipment can render different types of images for the same reading. In the traditional image, the white and black colors represent high- and low-intensity signals, respectively, with intermediate gray levels which are not visible to the naked eye. Other maps 
with false (inverted) colors of the same image were generated, which can improve tenuous color variations present in the traditional image to be differentiated. In all images, the demineralization depth is the same, although it differs in severity.

OCT is a method that allows qualitative and quantitative information, ${ }^{24}$ such as demineralization depth and size, to be obtained through 3D images, ${ }^{25}$ and shows great potential for future use in vivo. Also, as a non-invasive method, it provides a significant contribution to the achievement of standard, artificially produced caries-affected dentin that can be used in laboratory tests performed over a more clinically relevant substrate. Additional studies are required to validate this laboratory technique as a

\section{References}

1. Pugach MK, Strother J, Darling CL, Fried D, Gansky SA, Marshall SJ, et al. Dentin caries zones: mineral, structure, and properties. J Dent Res. 2009 Jan;88(1):71-6.

2. Haj-Ali R, Walker M, Williams K, Wang Y, Spencer P. Histomorphologic characterization of noncarious and cariesaffected dentin/adhesive interfaces. J Prosthodont. 2006 MarApr;15(2):82-8.

3. Mobarak EH, El-Korashy DI, Pashley DH. Effect of chlorhexidine concentrations on micro-shear bond strength of self-etch adhesive to normal and caries affected dentin. Am J Dent. 2010 Aug;23(4):217-22.

4. Kunawarote S, Nakajima M, Foxton RM, Tagami J. Effect of pretreatment with mildly acidic hypochlorous acid on adhesion to caries-affected dentin using a self-etch adhesive. Eur J Oral Sci. 2011 Feb;119(1):86-92.

5. Steiner-Oliveira C, Rodrigues LKA, Zanin ICJ, de Carvalho CL, Kamiya RU, Hara AT, et al. An in vitro microbial model associated with sucrose to produce dentin caries lesions. Cent Eur J Biol. 2011 Jan;6(3):414-21.

6. Gilmour ASM, Edmunds DH, Dummer PMH. The production of secondary caries-like lesions on cavity walls and the assessment of microleakage using an in vitro microbial caries system. J Oral Rehabil. 1990 Nov;17(6):573-8.

7. Gama-Teixeira A, Simionato MRL, Elian SN, Sobral MAP, Luz MAACL. Streptococcus mutans-induced secondary caries adjacent to glass ionomer cement, composite resin and amalgam restorations in vitro. Braz Oral Res. 2007 OctDec;21(4):368-74.

8. Le HM, Darling CL, Fried D. Automated analysis of lesion depth and integrated reflectivity in PS-OCT scans of tooth demineralization. Lasers Surg Med. 2010 Jan;42:62-8. protocol.

\section{Conclusions}

OCT has been shown to be an efficient and noninvasive method for the detection of the demineralization depth of caries-affected dentin produced through cariogenic challenge. It was observed that a 7-day period of cariogenic challenge can be considered adequate to obtain caries-affected dentin.

\section{Acknowledgements}

The authors acknowledge the financial support from FAPESP (grant \# 2009/07709-0), and Dr. Paulo Boschcov for his revision of the final version of the manuscript.

9. Fujimoto JG, Brezinski ME, Tearney GJ, Boppart SA, Bouma B, Hee MR, et al. Optical biopsy and imaging using optical coherence tomography. Nat Med. 1995 Sep;1(9):970-2.

10. Otis LL, Colston BW Jr, Everett MJ, Nathel H. Dental optical coherence tomography: a comparison of two in vitro systems. Dentomaxillofac Radiol. 2000 Mar;29(2):85-9.

11. Bakhsh TA, Sadr A, Shimada Y, Tagami J, Sumi Y. Noninvasive quantification of resin-dentin interfacial gaps using optical coherence tomography: validation against confocal microscopy. Dent Mater. 2011 Sep;27(9):915-25.

12. Perdigão J. Dentin bonding - Variables related to the clinical situation and the substrate treatment. Dent Mater. 2010 Feb(2);26:e24-e37.

13. Pereira PNR, Nunes MF, Miguez PA, Swift EJ Jr. Bond strengths of a 1-step self-etching system to caries-affected and normal dentin. Oper Dent. 2006 Nov-Dec;31(6):677-81.

14. Carvalho FG, Gonçalves LS, Carlo HL, Soares CJ, CorrerSobrinho L, Puppin-Rontani RM. Influence of sterilization method on the bond strength of caries-affected dentine. Braz Oral Res. 2009 Jan-Mar;23(1):11-6.

15. Marquezan M, Corrêa FNP, Sanabe ME, Rodrigues Filho LE, Hebling J, Guedes-Pinto AC, et al. Artificial methods of dentine caries induction: a hardness and morphological comparative study. Arch Oral Biol. 2009 Dec;54(12):1111-7.

16. Jones RS, Fried D. Remineralization of enamel caries can decrease optical reflectivity. J Dent Res. 2006 Sep;85(9):804-8.

17. Na J, Baek JH, Ryu SY, Lee C, Lee BH. Tomographic imaging of incipient dental caries using optical coherence tomography and comparison with various modalities. Opt Rev. 2009 Mar;16(4):426-31. 
18. Freitas AZ, Zezell DM, Mayer MPA, Ribeiro AC, Gomes ASL, Vieira Jr ND. Determination of dental decay rates with optical coherence tomography. Laser Phys. 2009 Dec;6(12):896-900.

19. Kolenbrander PE, Andersen RN, Blehert DS, Egland PG, Foster JS, Palmer RJ Jr. Communication among oral bacteria. Microbiol Mol Biol Rev. 2002 Sep;66(3):486-505.

20. Paster BJ, Boches SK, Galvin JL, Ericson RE, Lau CN, Levanos VA, et al. Bacterial diversity in human subgingival plaque. J Bacteriol. 2001 Jun;183(12):3770-83.

21. Banas JA, Vickerman M. Glucan-binding proteins of the oral streptococci. Crit Rev Oral Biol Med. 2003;14(2):89-99.

22. Lee SF, Li YH, Bowden GH. Detachment of Streptococcus mutans biofilm cells by an endogenous enzymatic activity. Infect Immun. 1996 Mar;64(3):1035-8.
23. Vats N, Lee SF. Active detachment of Streptococcus mutans cells adhered to epon-hydroxyapatite surfaces coated with salivary proteins in vitro. Arch Oral Biol. 2000 Apr;45(4):30514.

24. Gimbel C. Optical coherence tomography diagnostic imaging. Gen Dent. 2008 Nov-Dec;56(7):750-7.

25. Amaechi BT, Podoleanu AG, Komarov GN, Rogers JA, Higham SM, Jackson DA. Application of optical coherence tomography for imaging and assessment of early dental caries lesions. Laser Phys. 2003 May;13(5):703-10. 